\title{
Esophageal neuroendocrine carcinoma presenting as a rare cause of dysphagia
}

\author{
Sylvester Luu*1, Brian C. Benson ${ }^{2}$, Kelly A. Haeusler ${ }^{3}$, Robert O. Brady ${ }^{3}$, Katherine M. Cebe $^{3}$, Angelo H. Paredes ${ }^{2}$ \\ ${ }^{1}$ Department of Internal Medicine, Brooke Army Medical Center, San Antonio, TX, United States \\ ${ }^{2}$ Department of Gastroenterology, Brooke Army Medical Center, San Antonio, TX, United States \\ ${ }^{3}$ Department of Pathology, Brooke Army Medical Center, San Antonio, TX, United States
}

Received: January 23, 2018

DOI: $10.5430 /$ crim.v5n2p1
Accepted: March 12, $2018 \quad$ Online Published: March 20, 2018

URL: https://doi.org/10.5430/crim.v5n2p1

\begin{abstract}
A 60-year-old male with prior history of laryngeal carcinoma and active smoking presented with six months of solid food dysphagia. Endoscopy showed a large, friable gastroesophageal junction mass. Biopsies revealed a high-grade, poorlydifferentiated neuroendocrine carcinoma. He was subsequently started on platinum based chemotherapy and radiation therapy and his tumor decreased dramatically in size. This case is unique as neuroendocrine carcinomas (NECs) are rarely found in the esophagus and usually have a poor prognosis at time of diagnosis.
\end{abstract}

Key Words: Neuroendocrine carcinoma, Endoscopy, Esophagus, Dysphagia

\section{INTRODUCTION}

Neuroendocrine carcinomas (NECs) of the esophagus are rare, aggressive, poorly-understood malignancies that may present as a rare cause of dysphagia. The prognosis is generally poor as the tumor is usually advanced at the time of presentation and diagnosis.

\section{Case presentation}

A 60-year-old male presented with a six-month history of daily solid food dysphagia and a 10-pound unintentional weight loss. His past medical history was significant for stage 1 squamous cell carcinoma of the larynx diagnosed four years prior and treated with chemotherapy. He had a 30 pack-year smoking history and continued to smoke half a pack of cigarettes daily. His only medication was an ipratropium/albuterol 20-100 mg inhaler for chronic obstructive pulmonary disease. Endoscopy demonstrated a large villous tumor occupying approximately $50 \%$ of the circumference of the distal third of the esophagus extending $3 \mathrm{~cm}$ proximal to the Z-line (see Figure 1). There was a pseudo-lumen within the tumor that led into the stomach, and on retroflexed view there was a $5 \mathrm{~cm}$ portion of ulcerated tumor extending into the cardia (see Figure 2). Biopsy results showed squamous and oxyntic-gastric mucosa containing sheets and packets of pleomorphic cells (see Figure 3). The cells demonstrated immunohistochemical positivity for synaptophysin, chromogranin and CD56. Immunohistochemistry for Ki-67 revealed a proliferation index of greater than $90 \%$, classifying the tumor as a grade 3 or high-grade neuroendocrine carcinoma. Per the current National Comprehensive Cancer Network guidelines, this denotes a poor prognosis. ${ }^{[1]}$ Subsequent computed tomography revealed findings of a $7.1 \mathrm{~cm}$ $\times 6.8 \mathrm{~cm} \times 4.8 \mathrm{~cm}$ gastroesophageal junction mass with prominent regional lymph nodes and without radiologic ev-

\footnotetext{
*Correspondence: Sylvester Luu; Email: sylvesterluu@gmail.com; Address: Department of Internal Medicine, Brooke Army Medical Center, San Antonio, TX, United States.
} 
idence of metastatic disease. The patient was treated with neoadjuvant chemotherapy consisting of cisplatin, etoposide, and dexamethasone and concurrent radiation therapy prior to consideration of surgical resection. Follow up endoscopy six months later showed dramatic reduction in the size of the tumor with near resolution (see Figures 4 and 5).

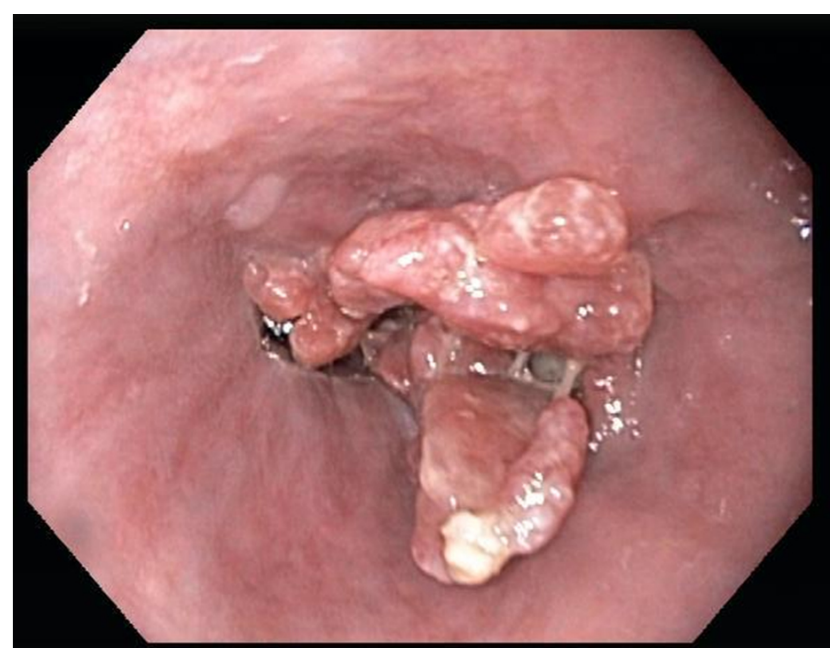

Figure 1. Villous tumor $3 \mathrm{~cm}$ proximal to z-line
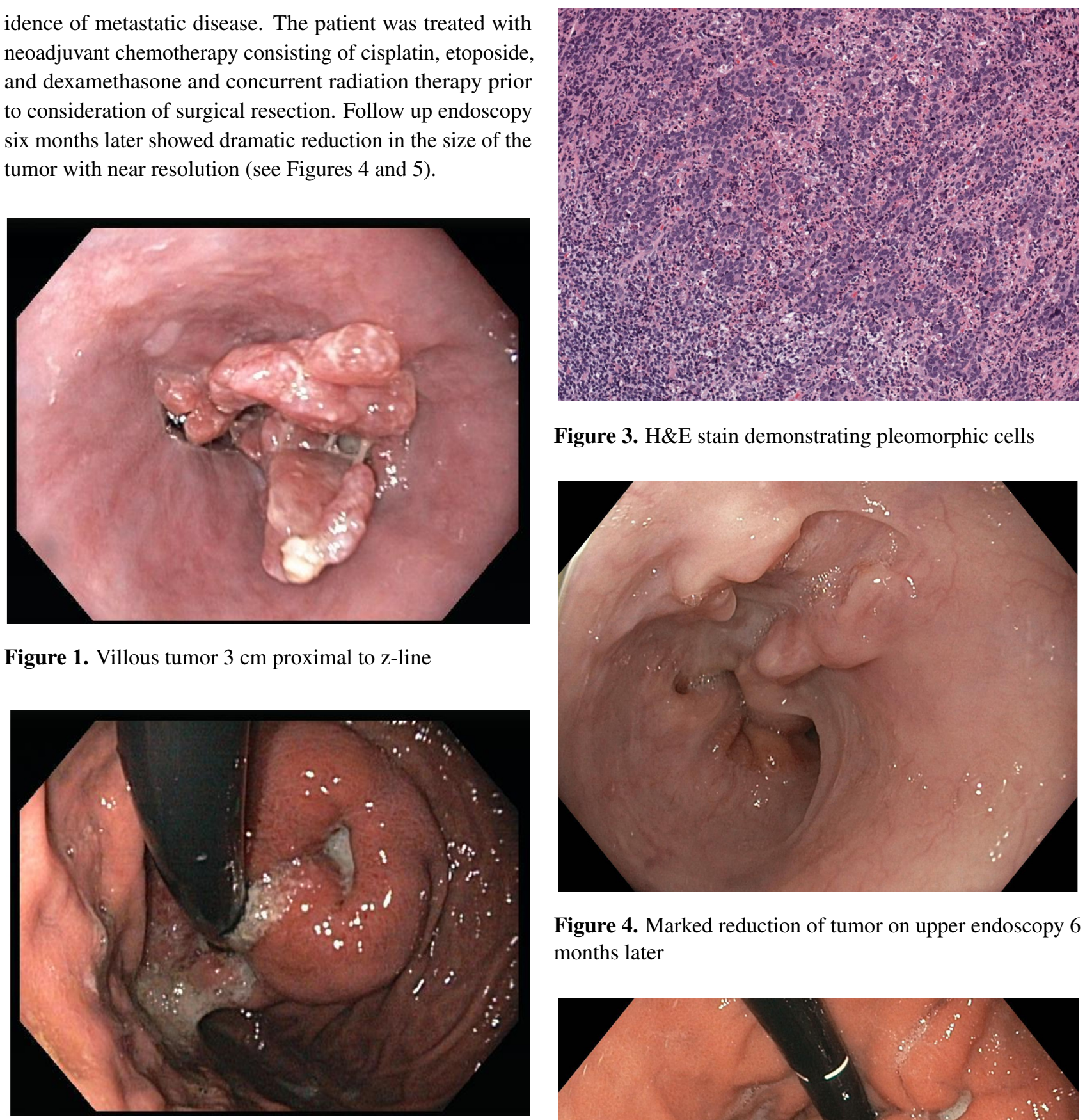

Figure 3. H\&E stain demonstrating pleomorphic cells

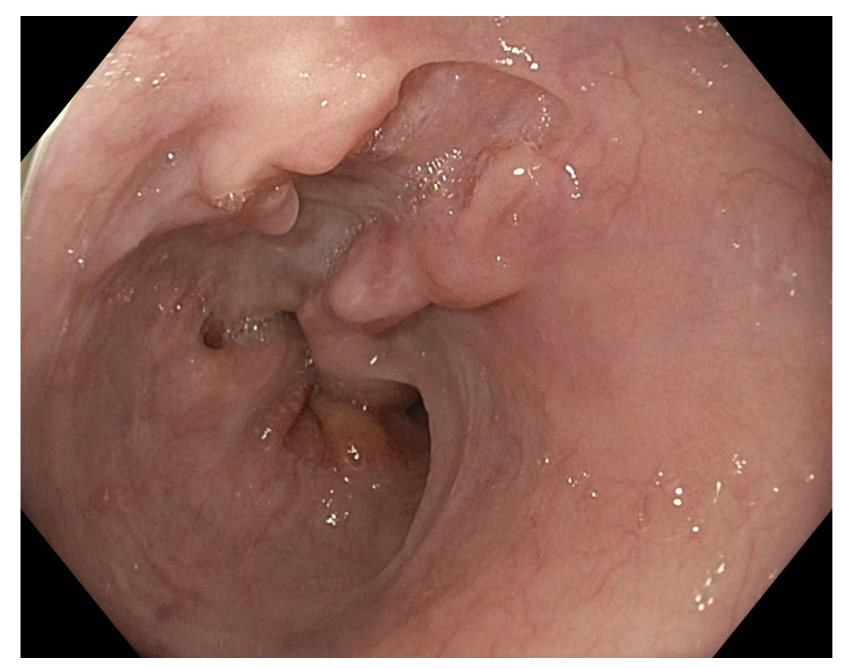

Figure 4. Marked reduction of tumor on upper endoscopy 6 months later

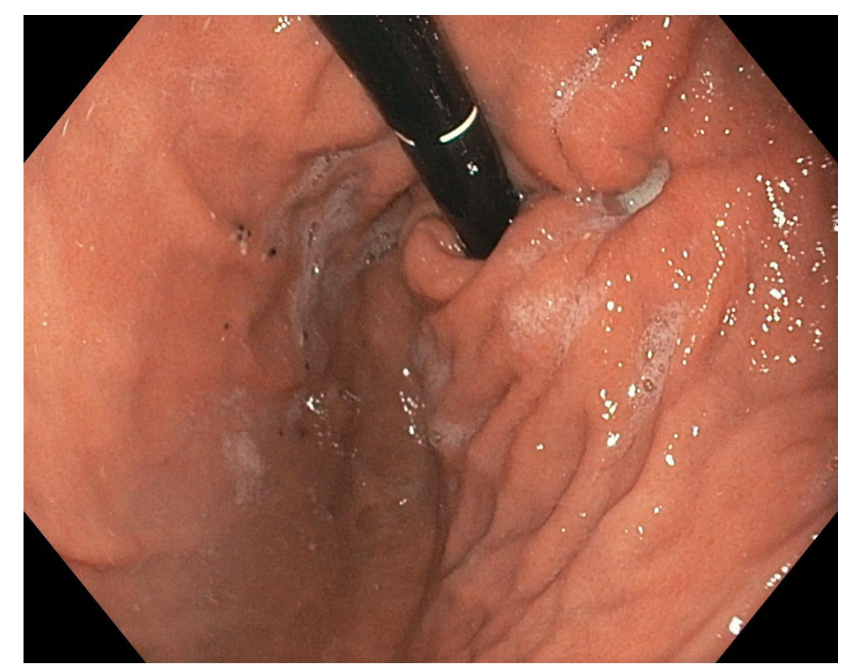

Figure $2.5 \mathrm{~cm}$ ulcerated tumor extending into the cardia on retroflexed view

\section{Discussion}

NECs are differentiated into two major categories: welldifferentiated and poorly differentiated. Well-differentiated NECs are commonly known as carcinoids while poorly differentiated NECs typically appear in the lung as small or large cell carcinomas. Esophageal NECs are a very rare cause of dysphagia and represent only $0.4 \%-2.0 \%$ of all esophageal malignancies. ${ }^{[2]}$ Additional uncommon locations are the jejunum, ileum, bladder, cervix, and prostate. ${ }^{[3]}$

Figure 5. Marked reduction of tumor on upper endoscopy 6 months later on retroflexed view 
Diagnostic criteria to classify a NECs as poorlydifferentiated per the European Neuroendocrine Tumor Society along with the World Health Organization is defined as: positive endocrine markers such as chromogranin A, synaptophysin, CD56, $>20$ per 10 high powered field mitotic figures, $>20 \% \mathrm{Ki}-67 \%$ proliferation index..$^{[2,4]}$

At the time of diagnosis, the prognosis is considered poor, with median survivals of 34,14 , and 5 months for those with localized, regional, and distant disease respectively. ${ }^{[5]}$ Treatment is subsequently guided based on the classification of limited disease (LD) versus extended disease (ED). ${ }^{[6]}$ Those with LD are generally treated based on small cell lung carcinoma paradigm with platinum-based chemotherapy, cisplatin and etoposide. Chemoradiation has been found to improve efficacy of therapy in those with small cell lung cancer, but has yet to be thoroughly studied in those with esophageal NECs. ${ }^{[7]}$ However, there are those that would extrapolate utilizing chemotherapy with concurrent radiation in the setting of a highly aggressive malignancy. Surgical excision is rarely effective as a sole therapy, but has been used in combination with subsequent chemotherapy. ${ }^{[8]}$
Esophageal NECs are still being characterized in their pathophysiology, presentation, and treatment; thus prompt recognition of symptoms is essential for diagnosis in this high mortality condition. Our patient responded to the current guideline directed therapy of chemotherapy and radiation based on small cell lung cancer practices and represents a valuable case for further understanding of a rare presentation.

\section{CONFlicts of InTEREST Disclosure}

The authors declare that they have no competing interests.

\section{CONSENT}

Patient consent was obtained for case publication.

\section{Disclosures}

The view(s) expressed herein are those of the author(s) and do not reflect the official policy or position of Brooke Army Medical Center, the U.S. Army Medical Department, the U.S. Army Office of the Surgeon General, the Department of the Army, the Department of the Air Force and Department of Defense or the U.S. Government.

\section{REFERENCES}

[1] National Comprehensive Cancer Network. Neuroendocrine Tumors (Version 3.2017). Available from: https://www.nccn.org/pro fessionals/physician_gls/pdf/neuroendocrine.pdf. Accessed September 27, 2017.

[2] Egashira A, Morita M, Kumagai R, et al. Neuroendocrine carcinoma of the esophagus: Clinicopathological and immunohistochemical features of 14 case. PLoS One. 2017; 12(3): e0173501. https://doi.org/10.1371/journal.pone.0173501

[3] Strosberg JR, Coppola D, Klimstra DS, et al. The NANETS Consensus Guidelines of the Diagnosis and Management of Poorly Differentiated (High-Grade) Extrapulmonary Neuroendocrine Carcinomas. Pancreas. 2010; 39(6): 799-800. https ://doi.org/10.1097/MP A. $0 \mathrm{~b} 013 \mathrm{e} 3181 \mathrm{ebb} 56 \mathrm{f}$

[4] Sorbye H, Strosberg J, Baudin E, et al. Gastroenteropancreatic highgrade neuroendocrine carcinoma. Cancer. 2014; 120: 2814-2823. https://doi.org/10.1002/cncr.28721

[5] Yao JC, Hassan M, Phan A, et al. One hundred years after "carcinoid": epidemiology of and prognostic factors for neuroendocrine tumors in 35,825 cases in the United States. J Clin Oncol. 2008; 26(18): 3063-3072. https://doi .org/10.1200/JC0.2007.15.4377

[6] Micke P, Faldum A, Metz T, et al. Staging small cell lung cancer: Veterans Administration Lung Study Group versus International Association for the Study of Lung Cancer-what limits limited disease? Lung Cancer. 2002; 37(3): 271-6. https://doi.org/10.1016/ S0169-5002(02)00072-7

[7] Takada M, Fukuoka M, Kawahara M, et al. Phase III study of concurrent versus sequential thoracic radiotherapy in combination with cisplatin and etoposide for limited-stage small-cell lung cancer: results of the Japan Clinical Oncology Group Study 9104. J Clin Oncol. 2002; 20(14): 3054-3060. https://doi.org/10.1200/JC0. 20 02.12 .071

[8] Casas F, Ferrer F, Farrus B, et al. Primary small cell carcinoma of the esophagus: a review of the literature with emphasis on therapy and prognosis. Cancer. 1997; 80(8): 13661372. https://doi.org/10.1002/(SICI) 1097-0142(199710 15) $80: 8<1366::$ AID-CNCR2>3.0.C0;2-D 